\title{
AlfabetiZAÇÃo E INCLUSÃo DIGITAL dE JOVENS E ADULTOS, COM O CÓDIGO DE TRÂNSITO BRASILEIRO COMO TEMA GERADOR
}

\author{
Ruth Bernardes de SANT'Ana \\ DANiel WILer Dias \\ Universidade Federal de São João del-Rei (UFSJ), São João del-Rei, \\ Minas Gerais, Brasil
}

Resumo: $\mathrm{O}$ artigo trata do relato de um curso de alfabetização de adultos, baseado em uma metodologia que buscou integrar elementos da pedagogia de Paulo Freire com o conhecimento de TICs (Tecnologias de Informação e Comunicação), tendo como tema gerador do conhecimento o Código de Trânsito Brasileiro (CTB). $O$ objetivo central consistiu na ampliação dos níveis de alfabetização/ letramento de adultos dos setores populares, a fim de que estes desenvolvessem competências muito dependentes da leitura e compreensão de texto, tal como as necessárias para a obtenção da CNH (Carteira Nacional de Habilitação). Os resultados mostram as dificuldades de uma proposta pedagógica muito condicionada às TICs, baseada no "aprender a aprender" e na exigência de que o aluno estude o material em casa. A conclusão é que esse modelo é insuficiente para a alfabetização dos diferentes segmentos de adultos iletrados brasileiros.

Palavras-Chave: Educação. Adultos. Pedagogia de Paulo Freire. TIC. 
INTRODUÇÃO

Um bairro popular de uma cidade histórica mineira de pequeno porte nos chamou atenção pela presença de pessoas analfabetas que, embora realizem atividades dependentes de leitura e escrita, recusaram-se, segundo informantes locais, a participar de cursos de alfabetização oferecidos na comunidade alguns anos atrás. Entre essas atividades, chamou-nos atenção a condução de veículos por pessoas do sexo masculino despossuídas de carteira de habilitação - algumas, inclusive, exercem trabalhos profissionais como manobristas e motoristas de caminhão e de trator. Isso não ocorre sem problemas, pois, por exemplo, quando essas pessoas precisam ir a cidades vizinhas, fazem-no em horários nos quais a presença da polícia na rodovia seja menos provável. Entretanto, uma vez ou outra, algum desses motoristas é flagrado pela polícia, e a consequência é a multa ou a apreensão do veículo pelo DETRAN. Nossa hipótese é que a recusa à participação em tais cursos se deveria à percepção de que isso seria humilhante para essas pessoas. Então, inferimos que um curso de alfabetização feito por meio de TICs, que integre o ensino de digitação, bem como o uso da internet e do CTB, pudesse ser mais atrativo para esse grupo.

Após conversarmos com algumas pessoas da comunidade e fazer um levantamento bibliográfico sobre a viabilidade desse tipo de projeto, decidimos fazer uma experiência, de caráter exploratório: oferecer um curso, sob a premissa de que o desenvolvimento de uma metodologia de uso do computador poderia colaborar, efetivamente, na educação de alunos adultos, para permitir acesso a vias de conhecimentos importantes para diferentes atividades sociais. Além disso, as TICs poderiam ser usadas como instrumento facilitador e motivador da aprendizagem, na medida em que o seu uso pode obedecer ao ritmo próprio de cada aluno, dentro e fora do curso.

Refletimos que, para além de obterem a carteira de motorista, essas pessoas poderiam desenvolver e ampliar suas formas de compreender o mundo em que vivem, não somente por meio do desenvolvimento da leitura e da escrita, mas também pelo acesso a novos conhecimentos favorecidos pelo acesso à internet. Dessa forma, o objetivo geral do projeto consistiu em desenvolver experiências educativas capazes de ajudar essas pessoas a ampliarem seus níveis de letramento com vistas à inclusão social em novos domínios da realidade. $O$ objetivo específico consistiu em desenvolver os conhecimentos necessários à obtenção da carteira nacional de habilitação e à formação de motoristas conscientes de seus direitos e deveres como cidadãos, bem como de seu papel na sociedade. 
O público-alvo foi constituído de pessoas que, por serem iletradas ou terem recebido escolarização insuficiente (analfabetos funcionais), não apresentavam as bases necessárias para se lançar na leitura e compreensão do CTB, mas desejavam ser habilitadas. Ao fim do curso, os alunos poderiam fazer matrícula na escola de formação de condutores (autoescola) e aumentar substancialmente sua chance de aprovação na prova teórica.

Antes de o curso começar, além de convidarmos pessoalmente as pessoas do público-alvo, foram afixados cartazes para convidar a população para a participação em uma reunião da Associação de Moradores de Bairro, que tinha esse assunto como um dos pontos de pauta. Nas conversas, vários homens demonstravam, direta ou indiretamente, que se ressentiam da falta de escolaridade, mas pareciam resistir à ideia de fazer o curso. Mesmo após essas conversas, em que buscávamos encorajá-los à participação no curso, alguns ainda recusaram a oferta, sob alegação de que "está bom assim" ou a "gente se vira, dá um jeito"; outros afirmaram que frequentariam o curso, mas não apareceram no primeiro dia, quando do preenchimento das vagas. Após o início das aulas, as esposas de alguns desses homens nos procuraram para explicar que eles se recusaram a se inscrever e, por isso, elas queriam substituílos no curso para conhecer o seu conteúdo e ensiná-lo aos seus maridos. Não pudemos aceitá-las, pois não havia mais vagas (a sala era pequena).

O curso aconteceu em um telecentro de um bairro popular da cidade, localizado no interior de uma escola de educação infantil. O total de alunos atendidos pelo curso foi 11 pessoas (seis mulheres e cinco homens); por idade, os jovens eram quatro pessoas de 22 a 28 anos e os adultos eram sete pessoas de 45 anos em diante, todos trabalhadores dos setores populares. As alunas tinham profissões como serviçais de pousada (copeira, camareira, faxineira), empregadas domésticas e serviços gerais; os alunos tinham as seguintes atividades profissionais: vigia de pousada, servente de pedreiro, trabalhador do campo, operador de draga (para extração de areia do rio) e condutor de trator e caminhão.

O curso teve duração de cinco meses, de junho a novembro de 2015, duas vezes por semana. Alguns meses após o fim do curso, fizemos visitas domiciliares e entrevistas com todos os estudantes, a fim de conhecer como viviam e ajudá-los a melhorar o uso do material didático (vídeos, apostilas) que tinham em mãos (alguns compraram computador), além de convidá-los para a participação nas entrevistas. Estas objetivaram compreender melhor os percursos biográficos e escolares desses ex-alunos, avaliar o curso e identificar as suas demandas de formação (a serem enviadas à prefeitura da cidade). 


\section{REFERENCIAL TEÓRICO-METODOLÓGICO}

O legado principal do pensamento pedagógico de Paulo Freire consiste na concepção da educação popular como ato político, na defesa da educação para a transformação social e para o desenvolvimento da cidadania do educando. Contra a noção de educação neutra, o trabalho de Freire busca explicitar o caráter político dos processos educativos, ao mesmo tempo em que faz oposição à "forma bancária" (em que quem ensina deposita conhecimento na cabeça do aprendente) de educação escolar. Para o autor, a educação de adultos exige uma abordagem que concebe o educando como alguém que tem uma história, uma inserção social, bem como práticas cotidianas constituídas nas suas relações com o trabalho e a produção social.

Hoje, o pensamento de Paulo Freire se mantém como referência importante para a Educação, pois sua contribuição ajuda a enriquecer as abordagens construtivas em Educação. O construtivismo crítico de Freire (GADOTTI, 1997) é mais facilmente perceptível na sua proposta de educação de adultos, que concebe que os conteúdos mais significativos da experiência social do grupo de alfabetizandos podem ser condensados em um tema gerador, do qual são escolhidas as frases e palavras sobre as quais repousam a alfabetização e a escrita. É a partir desse tema e do conjunto de significados políticos e sociais que o perpassam que a alfabetização/letramento se realiza. Por isso se diz que em Freire a aprendizagem da escrita envolve também a leitura da realidade social.

O trabalho de Paulo Freire estabelece uma crítica profunda à concepção até então dominante do processo de ensino-aprendizagem que concebe o educando como destinatário passivo de conhecimentos. Para Freire a alfabetização não ocorre desconectada do conteúdo da escrita, que deve ser significativo desde o momento que se inicia seu aprendizado. Em meados dos anos 1980, Ferreiro e Teberosky (1986) apresentaram um estudo sobre os aspectos psicogenéticos do desenvolvimento da alfabetização na criança, que também crítica os métodos mecânicos de aquisição da leitura e da escrita, em nome de uma proposta construtivista que concebe o educando como protagonista na construção de sua aprendizagem.

O construtivismo de Ferreiro e Teberosky (1986) se insere em um movimento de profundo questionamento tanto da metodologia quanto da teoria da alfabetização visível em Freire, cujo trabalho, no entanto, é reconhecido sobretudo por ter introduzido no domínio da educação o termo letramento, criado para designar a apropriação feita pelo indivíduo da cultura escrita, bem como sua relação com diferentes tipos e gêneros de materiais 
escritos existentes na sociedade (SOARES, 2004). Já a alfabetização envolve o processo de operar com sons e fonemas na composição da palavra, e o aprender a ler e a escrever frases e parágrafos simples. Assim, um indivíduo pode não saber ler e escrever o mínimo para ser considerado alfabetizado, isto é, ser analfabeto funcional (incapaz de ler um texto simples), mas ser, de certa forma, letrado, pois ele pode, de certa forma, envolver-se em práticas sociais de leitura e de escrita. Por isso, dizemos que um indivíduo é alfabetizado e letrado quando ultrapassa os limites da decodificação e da codificação do sistema de escrita, pois é capaz de manejar a língua em seu contexto social, de forma a ser entendido e entender seu interlocutor.

Embora alfabetização e letramento sejam considerados termos indissociáveis no fazer pedagógico, Soares (2004) compreende que apesar de designarem

processos interdependentes, indissociáveis e simultâneos, são processos de natureza fundamentalmente diferente, envolvendo conhecimentos, habilidades e competências específicos, que implicam formas de aprendizagem diferenciadas e, consequentemente, procedimentos diferenciados de ensino (SOARES, 2004, p. 23).

Quando atentamos na abordagem freiriana de alfabetização, percebemos que embora o seu foco seja a dimensão política do uso da língua em contexto social, nem por isso Freire deixe de atentar no processo de aprendizagem dos códigos, que constituem o sistema de escrita, de modo que a sua pedagogia também contempla a indissociabilidade entre a alfabetização e o letramento. Como foge aos objetivos deste artigo aprofundar essa discussão conceitual, aqui usamos termos como iletrado, alfabetização e letramento em um sentido mais geral, da mesma maneira como eles são comumente utilizados em textos de políticas públicas e/ou de relatos de práticas de alfabetização de adultos.

A partir da LDBN (Lei de Diretrizes e Bases da Educação Nacional), passou-se a falar de Educação de Jovens e Adultos como uma modalidade distinta do ensino regular, embora ela faça parte da Educação Básica (HADDAD; DI PIERRO, 2000). A inclusão desses dois universos de estudantes em uma mesma posição legal no interior das políticas públicas nacionais de educação acabou por engendrar a retomada da pedagogia freiriana, que passou a ser vista como uma fonte de inovação dos modos de acesso ao conhecimento, capaz de transcender os limites da formação escolar em moldes tradicionais, produtores do "insucesso escolar" e da defasagem idade-série. Ao refletir 
sobre esse segmento do alunado, Pierro, Joia e Ribeiro (2001) defendem que, referenciados em Freire, podemos forjar um campo de práticas e reflexão que

abarca processos formativos diversos, onde podem ser incluídas iniciativas visando a qualificação profissional, o desenvolvimento comunitário, a formação política e um sem número de questões culturais pautadas em outros espaços que não o escolar. Além disso, mesmo quando se focalizam os processos de escolarização de jovens e adultos, o cânone da escola regular, com seus tempos e espaços rigidamente delimitados, imediatamente se apresenta como problemático. Trata-se, de fato, de um campo pedagógico fronteiriço, que bem poderia ser aproveitado como terreno fértil para a inovação prática e teórica (DI PIERRO, JOIA; RIBEIRO, 2001, p. 58).

$\mathrm{Na}$ verdade, vivemos um processo de reflexão de como fazer educação popular em uma sociedade que muito se transformou desde os anos 1960. Por isso, embora a pedagogia de Paulo Freire referencie o trabalho que aqui apresentamos, este não teve a pretensão política do trabalho de alfabetização desenvolvido por esse mestre há mais de 50 anos, ou seja, o de impulsionar a consciência do educando de ingênua para crítica, a ponto de favorecer a emergência de uma consciência revolucionária (FREIRE, 1999). Porém, colocamo-nos entre aqueles que visam à atualização de sua pedagogia da autonomia com vistas a dar conta dos desafios da educação popular no presente. Concordamos com Di Pierro, Joia e Ribeiro (2001, p. 73), segundo os quais, "ao longo dos anos 80 e 90, as mudanças políticas, econômicas, sociais e culturais operadas dos cenários mundial e latino-americano desencadearam um processo, ainda inconcluso, de refundamentação teórico-prática do paradigma da educação popular".

A busca da renovação da prática da educação popular, nas duas últimas décadas, provocou a entrada da noção de alfabetização digital nas agendas de discussão dos programas de educação para todos, bem como na agenda de políticas públicas governamentais e não governamentais, enquanto componente essencial do combate ao iletrismo, na medida em que as TICS se disseminam em escala mundial. No interior do debate aberto sobre esse tema, Schwarzelmüller (2005) defende uma abordagem da inclusão digital que foge à concepção disseminada de uso das TICs em nome da exigência do mercado do trabalho. A inclusão digital, segundo essa autora, deve ter como objetivos: 1) promoção de competência informacional; 2) ampliação dos serviços universais para a cidadania; 3) desenvolvimento de conteúdos de ensino que tratem o local, integrando a linguagem, temas e discussões dos problemas regionais. Ao refletir sobre como esses objetivos podem ser promovidos por mediação das TICs, Schwarzelmüller propõe que 
os programas de inclusão digital se preocupem em oferecer atividades contextualizadas às características dos grupos sociais envolvidos de modo que a utilização da tecnologia seja feita de maneira conexa ao modo de vida desses grupos e às suas necessidades, e que promovam a troca e a socialização de experiências entre indivíduos e grupos, mediadas pela tecnologia (SCHWARZELMÜLLER, 2005, p. 2).

Foge aos objetivos deste trabalho problematizar a noção de inclusão digital e investigar se os cursos de educação de adultos, na maneira como ocorrem, de fato permitem ao aluno sair da condição de excluído social da comunicação mediada pelas TICs. Para os interessados em conhecer mais sobre este assunto, um debate atualizado sobre inclusão/exclusão digital pode ser encontrado em publicação organizada por Bonilla e Pretto (2011).

Nosso trabalho se inscreve entre aqueles que se referenciam na noção de "temas geradores" de Freire, adaptada ao ensino mediado pelas TICs. Esses temas são estabelecidos de antemão com vistas a problematizar questões ligadas ao mundo atual. Esse tipo de "refundamentação" do referencial freiriano pode ser percebido em um trabalho pioneiro de grande porte desenvolvido pelo programa do MOVA-digital, que teve sua primeira experiência desenvolvida em São Paulo, no período de 2001-2004, no governo municipal de Marta Suplicy. Os seus pressupostos político-pedagógicos repousam sob a ideia de que

todo aquele que não tem acesso a esse mundo da informação é considerado um "analfabeto digital". A exclusão digital é uma forma de dominação política e contribui para a manutenção e a ampliação das desigualdades. Daí a necessidade de uma alfabetização digital, que não se restringe ao domínio de uma tecnologia, mas que vai muito além. O MOVA-Digital inspirou-se nos "temas geradores" do Método Paulo Freire, problematizando a nova realidade do novo mundo digital, ao mesmo tempo em que o alfabetizando se apropria dos instrumentais da virtualidade: navegar na internet, trabalhar com um processador de texto, enviar uma mensagem etc. (GADOTTI, 2008, p. 137).

O termo Tecnologias de Informação e de Comunicação (TICs) é comumente utilizado para se referir a um conjunto de dispositivos técnicos modernos criados para mediar os processos de comunicação, de transmissão e tratamento de informação entre as pessoas, sendo que esses processos ocorrem sobretudo por computadores, conexões entre redes de computadores e internet e são realizados por programas (conjunto ordenado de instruções, escritas em uma linguagem de programação, permitindo a um sistema executar uma tarefa ou resolver um problema automaticamente). Os seus recursos tecnológicos podem ser integrados entre si por meio de 
conexões entre funções operacionais diversas, permitindo o fomento de diferentes atividades sociais, como a produção, o comércio, a pesquisa científica, o ensino e a aprendizagem presenciais ou a distância etc.

A forma de incorporação das TICs ao processo de ensino e aprendizagem com adultos iletrados é sempre um grande desafio, pois fazer a seleção e transformação da informação em conhecimento, de acordo com os fundamentos político-pedagógicos do projeto e do público-alvo, exige escolhas estratégicas, do ponto de vista das relações humanas mediadas pela máquina, do desenvolvimento de métodos e técnicas de ensino, produção de material didático etc. No caso do MOVA-Digital, a

metodologia utilizada foi o "grupo de formação", com apoio de universitários, onde foram discutidos, entre outros, os seguintes temas: "conhecimento centralizado x descentralizado", "informação para todos x desinformação", "dominação x libertação tecnológica", "emprego x desemprego tecnológico". Tais temas foram debatidos, escritos, vividos e experimentados nos teclados, telas, 139 mensagens, chats e gravações em disquetes (GADOTTI, 2008, p. 137-138).

Identificamos que o caminho para agregar a dimensão da cidadania ao curso por nós ministrado seria favorecer aos alunos a compreensão do ato de dirigir um veículo como um ato de responsabilidade social e política dado na relação das pessoas com a natureza (o impacto no meio-ambiente) e com as outras pessoas (pedestres, ciclistas e pessoas que conduzem veículos), ao mesmo tempo inserindo-se o ato de dirigir em um contexto local e globalmente mais amplo, perpassado por relações de poder (diferenças de gênero na condução do veículo, por exemplo). A aposta política incidiu sobre a capacidade de essas pessoas generalizarem essa reflexão para outros domínios da vida social.

A elaboração do programa do curso teve como orientação essa necessidade e a busca de novos recursos metodológicos para serem utilizados nas aulas, inclusive para ajudar o grupo a fazer uso do computador e dos recursos da internet, já que a maioria dos alunos não tinha contato direto com as TICs e, por vezes, mostrava uma percepção errônea das relações entre o computador e a internet. Durante as primeiras aulas do curso, dois alunos disseram que possuíam computador, mas não o usavam, pois não tinham internet em casa, como se houvesse uma dependência total entre os dois instrumentos de comunicação. Essa visão era compartilhada por várias pessoas. Uma aluna nos declarou que, meses antes, chegara a comprar um computador caro, mas o vendera ao saber que a localização de sua casa impediria o acesso à internet. 


\section{MateriaIS PedAGÓGICOS}

Buscamos desenvolver atividades comuns a todos os alunos, porém individualizadas segundo as necessidades de cada um. Buscamos, ainda, ensinar a todos o mesmo conteúdo, porém com variação no ritmo e na oferta de atividades. Para tal, não classificamos os níveis de letramento dos alunos por sondagem dos seus níveis conceituais linguísticos, como indicam Ferreiro e Teberosky (1986), conforme uma prática muito difundida no Brasil. Entretanto, procuramos modular as tarefas propostas no desenrolar da interação professor-aluno. Ou seja, o caminho trilhado pelo processo de produção do conhecimento dependia, sobretudo, do que o aluno expressasse no contexto da interação com o professor. Assim, esforçávamo-nos em adaptar o conteúdo ao nível de letramento de cada um. Construímos metodologias de transposição "didática", ajustadas a cada aluno em particular, a fim de inovar a forma de superação da transposição mecânica de conteúdos e procedimentos, por vezes ainda usada no ensino regular.

Assim, elaboramos um curso que contou com materiais pedagógicos, como vídeos, apostilas e provas simuladas, encontrados na internet. Os vídeos baixados da internet foram passados para a linguagem usada na produção de DVD de filmes, a fim de que todos pudessem assistir às aulas em suas casas, já que todos os alunos tinham aparelhos de reprodução de DVDs. Ou seja, mudamos o formato dos vídeos para que fossem abertos tanto em aparelhos de DVD como em computadores, de modo que o aluno utilizasse o dispositivo tecnológico que ele tivesse em casa.

Os textos geradores da reflexão e do conhecimento, bem como os conceitos que neles se inserem, foram baseados no material didático utilizado, ou seja, a apostila do Código de Trânsito e os vídeos extraídos da internet. As matérias tratadas pelo CTB já tiveram a "transposição didática" para o ensino em vídeo, por autoescolas. O material das aulas baixadas da internet e o conteúdo foram organizados dentro dos seguintes temas: legislação, direção defensiva, primeiros socorros, meio ambiente e mecânica.

Para aqueles alunos que mostravam dificuldade em associar corretamente certos os sons à escrita, e por isso trocavam letras, baixamos da internet também vídeos específicos. Após intensa procura, encontramos vídeos de fonética adequados às pessoas adultas, em sites dedicados ao ensino de português para estrangeiros. Fizemos um pouco de leitura fonética com os alunos a fim de ensinar para que ela serve e como utilizá-la nos seus estudos em casa. 
Quando fomos à escola conhecer a sala e os computadores do telecentro, soubemos que havia somente um computador (que era utilizado pelas professoras da escola) e que os demais se encontravam no chão da Secretaria Municipal da Educação. Quando eles retornaram, nós os testamos e vimos que tinham vários problemas de funcionamento (que procuramos sanar), além de a potência do sinal de internet se limitar a somente um computador (e ainda com lentidão), embora o telecentro fosse projetado para 12 computadores. Solicitamos à dirigente da escola que pedisse aos órgãos competentes a resolução desses problemas, mas isto não ocorreu. $\mathrm{O}$ sinal de internet melhorou somente mais de um mês após o início do curso, quando uma das nossas alunas foi a uma reunião chamada pela prefeitura (dedicada à escuta dos problemas do bairro) e se queixou da situação. A partir daí, pudemos conectar três dos dez computadores em rede, já que a intensidade do sinal aumentou um pouco. Por causa da fraqueza do sinal, tivemos de abandonar a intenção de despender para o trabalho na internet ao menos meia hora de cada dia do curso em seu primeiro mês.

Na primeira aula, inicialmente mostramos em um datashow acoplado a um computador os recursos da internet e da informática que eles aprenderiam a usar no transcorrer do curso. A partir do encontro seguinte, a cada aula eles recebiam uma folha com os exercícios previstos para aquela data. Nas primeiras aulas, após explorarem um pouco o teclado do computador, eles escreviam um pequeno cabeçalho, ou seja, digitavam seu nome, o nome da cidade e a data. Caso quisessem, podiam acrescentar outras informações de seu interesse, como o nome dos filhos e cônjuges. Depois disso, eles executavam as tarefas na sequência sugerida por nós ou escolhida por eles. Essa fase nos permitiu identificar se eles liam e escreviam, se liam e não escreviam, e até que ponto.

Nas duas semanas seguintes, enquanto aguardávamos que os alunos garantissem a cópia da apostila e nos trouxessem um DVD para a cópia das aulas em vídeo, procuramos atender cada aluno na leitura e na escrita para oferecer meios para cada um avançar. Os que não finalizavam as tarefas em um dia, continuavam-nas no dia seguinte; se o aluno faltasse, poderia seguir as aulas, pois os exercícios não eram completamente progressivos, já que em cada folha de atividades coexistiam exercícios simples e complexos, que nós adaptávamos conforme o aluno.

Aqui priorizamos enfatizar como se deu o trabalho com os alunos com menor nível de alfabetização/letramento. Na primeira semana, os alunos procuraram no teclado as vogais AEIOU e, depois, as primeiras letras do alfabeto, $A B C D E$. Na sequência, pedimos que digitassem palavras ou frases, por nós 
sugeridas, iniciadas por essas letras, todas ligadas ao código do Trânsito como, por exemplo, aprovação, exame, inscrição, órgão, volante, advertência, baliza, carro, direção defensiva, Estado. Seguindo a abordagem de Paulo Freire, procuramos também palavras de maior nível de variedade fonética. $\mathrm{Na}$ folha também constavam exercícios de digitação. Trabalhávamos com os alunos individualmente, de modo que antes, após ou durante a digitação das palavras e frases por eles, líamos e pedíamos que lessem, procurando trabalhar a associação entre a letra e o som quando ela não existia ainda.

Na segunda semana, continuamos com o método. Palavras iniciadas com FGHIJ e QWERT POIUY, todas originárias do CTB, foram propostas por nós, em uma mistura de exercícios de digitação e alfabetização ao mesmo tempo. Ao ler essas letras digitadas, eles poderiam corrigir os erros de soletração fonética porventura existentes. Após isso, o aluno procuraria escrever palavras sobre qualquer assunto de seu interesse, desde que tivessem essas letras na sua composição.

$\mathrm{Na}$ terceira semana, as atividades com a internet começaram, de modo que cada dia um grupo de três alunos permanecia cerca de uma hora com um dos professores para aprender a navegar e fazer pesquisas pela internet, já que o sinal era suficiente somente para um computador.

$\mathrm{Na}$ quarta semana, todos os alunos já tinham o arquivo dos vídeos em DVD para assistir às primeiras aulas de vídeo em casa, material que intentávamos começar a explorar diretamente na semana seguinte. Pensamos que, a partir do momento em que os alunos tivessem o material nas mãos, selecionaríamos, entre as palavras e frases mais significativas para a compreensão do assunto, as de base para as lições $\bigotimes$ em torno de 20 palavras. Depois de composto o universo das palavras significativas, estas seriam apresentadas em cartazes, afixados na sala, com destaque para palavras, frases e imagens. Então, em grupo, dar-se-ia a discussão para elaboração do significado dentro do conteúdo escolhido.

Contudo, o grupo não caminhou como havíamos projetado, já que somente um aluno assistia aos vídeos em casa. Então, adaptamos o método a essa realidade, de maneira que assistíamos aos vídeos e os debatíamos juntos em classe, com pausas no desenrolar da sequência do filme para retomar, discutir e revisar o conteúdo mais importante, ressaltando-se as palavras mais importantes para o desenvolvimento da escrita. Essa atividade em grupo é a que mais favorece o diálogo e a politização de assuntos tratados, constituindo um espaço de debate importante para aqueles educadores que consideram que alfabetizar é também politizar. Para tal, procuramos tratar situações inseridas na realidade do trânsito brasileiro com o intuito de abrir 
perspectivas para a análise crítica consciente de problemas locais, regionais e nacionais a eles articulados.

Parte do conteúdo era retomada nas frases usadas na digitação. Durante todo o processo, pedimos ao aluno que lesse o que escrevera e, se fosse necessário, líamos junto com ele a palavra inteira, parte dela, sílabas e letras (quando ele trocava letras) e a frase da qual ela fazia parte. A crítica acadêmica à silabação na pedagogia de Freire nos levou a lançar mão da silabação somente no momento da leitura, enfocando a palavra antes e depois da silabação.

Entre outros conhecimentos, ensinamos como abrir uma conta de e-mail e como usá-la para comunicação entre nós e com outras pessoas. Aproveitaremos também para ensinar a pesquisa na internet como forma de acesso ao conhecimento sobre assuntos de interesse dos alunos. Por fim, nas últimas semanas do curso, os alunos também entravam na rede de internet para fazer os testes do DETRAN on-line.

\section{Resultados e DISCUSSÃo}

Refletimos que a dimensão relacional e pedagógica da aprendizagem é muito importante para ajudar adultos relutantes a lidarem com sua aversão a tudo o que lembra o mundo escolar e com o processo de invalidação sofrido por eles em decorrência da falta de escolaridade. Observamos que outros fatores entram em jogo na situação dentro da classe. Apesar de o clima dos encontros ser alegre e descontraído, em uma atmosfera de diálogo, respeito, colaboração e confiança, isso não garante tudo, pois há elementos do mundo cultural do aluno que são difíceis de abordar, direta ou indiretamente, em um curso de curta duração, mas que refletimos aqui.

Percebemos que as pessoas muito pouco letradas eram todas do sexo masculino. Coincidentemente, tinham comportamentos diferentes das mulheres no interior da sala de aula. Elas sabiam um pouco mais do que os homens, mas é difícil saber se é por causa disso que elas se mostravam comparativamente muito mais tranquilas, já que a ansiedade masculina foi o aspecto mais visível na interação face a face com o professor. Um dos motivos dessa ansiedade, provavelmente, foi o temor do fracasso diante de tarefas consideradas complexas, pois eles teriam de aprender a ler, escrever e usar o computador ao mesmo tempo. Além do cansaço, o fato de não terem feito nenhuma tarefa em casa e de progredirem mais lentamente parecia deixá-los pouco à vontade, haja vista o evidente nervosismo masculino diante desse tipo de situação. 
Como os professores deviam se dedicar mais a esses alunos menos avançados na alfabetização do que aos demais (maioria feminina), isso parecia ser vivido por esses alunos, que precisavam de mais tempo e de auxílio do professor para a realização cada tarefa proposta, como um "furto" do tempo da classe, ao mesmo tempo em que eles pareciam se sentir diminuídos por saberem menos (ouvimos um dizer à esposa que gostaria de deixar o curso porque outros sabiam mais do que ele). É como se houvesse um autojulgamento depreciativo da própria performance por parte dos homens, enquanto as mulheres pareciam estar mais despreocupadas com um suposto julgamento de seu desempenho. Isso parece indicar que, entre os homens, podemos encontrar uma sensibilidade aguda, provavelmente resultante da socialização de gênero, diante das tarefas mais propriamente escolares. $\mathrm{O}$ julgamento depreciativo pode ser o resultado decorrente da lembrança do veredito escolar (todos frequentaram escolas, mas não foram alfabetizados) incapacitante vivido no passado, que é sentido como uma incapacidade. Nas entrevistas feitas com os alunos, somente um atribuiu sua condição de iletrismo à escola, atribuindo a ela a responsabilidade pelo fracasso escolar ocorrido em sua trajetória de vida.

Só tivemos uma evasão feminina, mas se tratava de uma mulher com doze filhos, que trabalhava de segunda-feira a domingo (serviço de jardinagem, tinha uma banca de comida em uma praça da cidade nos fins de semana etc.), e que, após algumas semanas, decidiu se inscrever na autoescola. Permaneceu até a última aula somente um aluno do sexo masculino (o único que estudava em casa e não faltava às aulas), que entrou praticamente analfabeto, mas terminou o curso alfabetizado e com bastante conhecimento sobre o Código de Trânsito. Depois disso, seu letramento continuou, pois ele passou a navegar pela internet para desenvolver novos modelos de peças de artesanato para a sua oficina, e estudava como abrir um site gratuito para realizar vendas virtuais.

A experiência desenvolvida nos levou a questionar a eficácia de cursos de curta duração, que exigem do aluno a realização de parte expressiva das atividades em casa. É um modelo que demanda muito do educando, na medida em que o obriga a mudar sua rotina e reservar grande parte do tempo para se dedicar a tarefas que exigem o desenvolvimento de novos esquemas de pensamento e ação (assistir aos vídeos, pausá-los, tentar escrever as frases mais importantes etc.). Ou seja, a utilização de um modelo educativo do \aprender a aprender $\bigotimes$, um pressuposto partilhado com a pedagogia da EAD (educação a distância), parece-nos incapaz de contemplar alunos pouco letrados. A relação da educação não-presencial com a tecnologia nos parece 
uma aposta ousada para os programas de alfabetização, dadas as dificuldades identificadas no curso por nós ministrado, pois tal relação supõe alunos que trabalhem sozinhos a maior parte do tempo e que desenvolvam novas rotinas, novos esquemas de pensamento e ação, exigindo-lhes o desenvolvimento de novas disposições culturais em curto tempo.

Além disso, trabalhar com alunos com diferentes graus de alfabetização, em um modelo de individualização do processo de aprendizagem, exigiria um maior número de professores/monitores para dar conta do descompasso que as necessidades de cada aluno impunham em certos momentos. Caso contrário, o curso ficaria demasiadamente moroso para os estudantes mais avançados e acelerado para os mais lentos. Isso não seria um grande problema se aqueles mais adiantados pudessem navegar na internet, mas isso era impossível devido à insuficiência de sinal. Outro problema consistia no sistema operacional Linux, que nos parecia pouco intuitivo e difícil de usar. Além disso, sua aprendizagem não podia ser generalizada facilmente para outros contextos, pois a maioria dos computadores utiliza o sistema operacional Windows.

Mesmo se o curso tivesse atingido o objetivo de promover uma alfabetização/letramento que permitisse o conhecimento mínimo, a todos os alunos, sobre os recursos do computador e da internet, aliado ao desenvolvimento básico de leitura e escrita, os progressos obtidos poderiam se perder sem atividades de "pós-alfabetização" que permitissem ampliar e sedimentar essas competências.

Apesar disso, percebemos que o nível de alfabetização digital (digitar, usar recursos básicos de informática, pesquisar na internet, escrever, enviar e receber e-mails) pretendido pelo curso foi atingido por aqueles que permaneceram até as últimas semanas. Porém, avançar além desse mínimo exige estar bem alfabetizado para compreender os conceitos ligados à nova linguagem trazida pelas TICs. Além disso, consolidar as competências ligadas ao uso das TICs sem ter computador/internet em casa e sem haver telecentros preparados para o uso comunitário torna-se muito difícil.

Há telecentros inoperantes e gestores municipais pouco preparados para impulsionar o desenvolvimento dos programas sociais de inclusão digital estabelecidos nos níveis federal e estadual para as pessoas mais desmunidas socialmente. Por isso, na formulação dos projetos, é arriscado apostar demais nesses recursos sem a certeza de que funcionam realmente. Um curso mais longo e com o conteúdo mais escalonado, iniciado com a escrita sem computador, de modo que a introdução ao uso do computador fosse paulatina, segundo as condições concretas da infraestrutura local, poderia ser uma aposta mais realista. 
Por último, não podemos deixar de tocar na questão da oferta de um curso baseado no voluntariado. No momento da formulação do projeto, foi acordado que o primeiro autor deste artigo trabalharia com um psicólogo e um estagiário durante um mês, que estes dariam continuidade ao trabalho durante uma longa viagem feita por aquele e que durante esse tempo a equipe continuaria a discutir o projeto on-line (via Skype). Mas o psicólogo desertou na terceira semana do curso, alegando ter decidido desenvolver outra atividade na cidade, o que contribuiu para dificultar o trabalho durante o período de ausência física do primeiro autor.

A educação de adultos iletrados, como uma "segunda chance", muito frequentemente esbarra no problema de financiamento, do qual faz parte a dificuldade de preparação de material capaz de atingir, igualmente, dos mais jovens (pessoas abaixo de 40 anos) aos mais velhos e, ao mesmo tempo, de dar conta da diferença de nível de letramento entre eles. $O$ fato de o curso depender do voluntariado, acompanhado ou não de uma pequena remuneração, pode ser mais um fator de precarização que induz à oferta de cursos pouco adequados para comunidades socialmente desfavorecidas. A conclusão é que esse modelo é insuficiente para a alfabetização dos diferentes segmentos de adultos iletrados brasileiros.

Artigo recebido em: 07/11/2016

Aprovado para publicação em: 12/03/2017

\section{LITERACY AND DIGITAL INCLUSION OF YOUNGSTERS AND ADULTS, WITH BRAZILIAN TRAFFIC CODE AS A GENERATOR THEME}

ABSTRACT: This paper deals with the report of an adult literacy course, based on a methodology which sought to integrate elements of Paulo Freire's pedagogy with knowledge about ICT (Information and Communication Technologies), having the knowledge about Brazilian Traffic Code (CTB) as its generator theme. The main objective was the expansion of literacy levels among adults from popular sectors, so that they could develop skills that are very dependent on reading and reading comprehension, such as the acquirement of CNH (National Driver's License). The results show the difficulties of a pedagogical proposition that is very dependent on ICT, which is based on the "learning to learn" and obliges the student to study the material at home. In conclusion, this model is not enough to educate different groups of illiterate Brazilian adults.

KeYwoRDs: Education. Adults. Paulo Freire's Pedagogy. ICT. 
ALFABETIZACIÓN E INCLUSIÓN DIGITAL DE JÓVENES Y ADULTOS, ADOPTANDO COMO TEMA GENERADOR EL CÓDIGO DE TRÁNSITO BRASILEÑO

RESUMEN: El artículo se ocupa del relato de un curso de alfabetización para adultos, basado en una metodología que intentó integrar elementos de la pedagogía de Paulo Freire al conocimiento de las TIC (Tecnologías de la Información y Comunicación), adoptando como tema generador los conocimientos sobre el Código de Tránsito Brasileño (CTB). El objetivo principal fue mejorar los niveles de alfabetización/ letramento de adultos de sectores populares, con la finalidad de que desarrollen habilidades que dependen de la lectura y la comprensión lectora, tales como la obtención de la CNH (Licencia Nacional para conducir). Los resultados muestran las dificultades de un enfoque pedagógico muy limitado a las TIC, basado en "aprender a aprender" y que exige del aluno estudiar su material en casa. La conclusión es que este modelo es insuficiente para la alfabetización de los diferentes segmentos de adultos analfabetos brasileños.

Palabras clave: Educación. Adultos. Pedagogía. Paulo Freire. TIC.

\section{REFERÊNCIAS}

BONILLA, M. H S; PRETTO, N. de L. (Org.). Inclusão digital: polêmica contemporânea. Salvador: EDUFBA, 2011.v. 2.

DI PIERRO, M. C. JOIA, O. RIBEIRO, V. M. Visões da educação de jovens e adultos no Brasil. Cadernos Cedes, Campinas, ano 21, n. 55, nov. 2001. Disponível em: <http:// www.scielo.br/pdf/ccedes/v21n55/5541>. Acesso em: 02 jul. 2015.

FERREIRO, E; TEBEROSKY, A. Psicogênese da língua escrita. Porto Alegre: Artmed, 1986.

FREIRE, P. Educação como prática da liberdade. 23. ed. Rio de Janeiro: Paz e Terra, 1999.

GADOTTI, M. Mova, por um Brasil alfabetizado. São Paulo: Instituto Paulo Freire, 2008. Disponível em: <http://www.acervo.paulofreire.org:8080/jspui/bitstream/7891/3084/1/FPF_PTPF_12_081.pdf>. Acesso em: 01 jun. 2015.

. Lições de Freire. Revista da Faculdade de Educação, São Paulo, n. 23, v. 1-2, 1997. Disponível em: <https://dx.doi.org/10.1590/S0102-25551997000100002>. Acesso em: 02 nov. 2016.

HADDAD, S.; DI PIERRO, M. C. Escolarização de jovens e adultos. Revista Brasileira de Educação, Rio de Janeiro, n. 14, p. 108-130, maio/ago. 2000. Disponível em: <http:// www.scielo.br/pdf/rbedu/n14/n14a07>. Acesso em: 02 nov. 2016.

SCHWARZELMÜLLER, A. F. Inclusão digital: uma abordagem alternativa. In: ENCONTRO NACIONAL DE CIÊNCIA DA INFORMAÇÃO, 6., 2005, Salvador. Anais...Salvador> CINFORM, 2005. Disponível em: <http://www.cinform-anteriores.ufba.br/vi_anais/ docs/AnnaSchwarzelmuller.pdf>. Acesso em: 02 jul. 2015. 
SOARES, M. Letramento e alfabetização: as muitas facetas. Revista Brasileira de Educação, Rio de Janeiro, n.25, p. 5-17, 2004. Disponível em <http://dx.doi.org/10.1590/ S1413-24782004000100002>. Acesso em: 02 jul. 2015.

Ruth Bernardes de Sant'Ana: Professor Associado do Laboratório de Pesquisas e Intervenção Psicossocial (LAPIP/UFSJ). Tem experiência nas áreas de Psicologia Social e Educação, pesquisando principalmente os seguintes temas: psicologia social, abordagens interacionista na psicologia social e na educação (interacionismo simbólico, etnometodologia etc.) infância, educação infantil, jovens e escolarização.

E-mail: ruthbs@ufjs.edu.br

DaNIEL WILER DIAS: graduando de Psicologia na UFSJ. Tem experiência em ensino de informática, processamento digital, rede de computadores $e$ internet.

E-mail:smdwdi@smail.com 